\title{
HERMENÉUTICA DEL LENGUAJE Y SIMBOLISMO
}

\author{
Luis GARAGAIZA ARRIZABALAGA \\ Universidad del País Vasco
}

\begin{abstract}
RESUMEN. En este artículo hacemos una presentación de la hermenéutica de H.-G. Gadamer a partir de su concepción del lenguaje como "medium" (y no mero "instrumento") en el que tiene lugar la interpretación-comprensión y la experiencia humana del mundo. Abordamos también la problemática del simbolismo como factor constiturivo de la cultura presentándola, con la ayuda de autores como C. G. Jung y E. Cassirer, desde una perspectiva psico-antropológica y finalmente apuntamos la propuesta elaborada por $\mathrm{A}$. Ortiz-Osés de reunir ambas perspectivas, la de la hermenéutica filosófica y la del simbolismo, en una hermenéutica simbólica de la cultura.
\end{abstract}

\section{La crisis de la cultura europea}

La filosofía del último siglo puede ser comprendida como el intento de dar respuesta teórica a la crisis global que coincidiendo con el paso del siglo XIX al $\mathrm{XX}$ afectó a toda la cultura europea. Dicha crisis consiste en una pérdida de confianza en la capacidad del lenguaje establecido para articular y comunicar las inquietudes y problemas de las nuevas generaciones. La tradición europea pierde el contacto con la vida emergente bloqueándose y encerrándose en sí misma, incapaz de integrar la novedad: se torna estéril y comienza a descomponerse, por lo que no es de extrañar que R. Musil inventase el nombre de «Kakania» para referirse a la "buena sociedad" del Imperio de los Habsburgo ${ }^{1}$.

${ }^{1}$ Cfr. A. JANIK y S. TOUlmin, La Viena de Wittgenstein, Taurus, Madrid, 1989. Cfr. así mismo J. GaRCfa LEaL, Arte y conocimiento, Universidad de Granada, Granada, 1995. 
En este contexto tiene lugar la «revolución lingüística» de la filosofía: la mirada filosófica se concentra críticamente sobre el lenguaje intentando dar cuenta del hecho de que el (supuesto) instrumento de comunicación se haya tornado opaco. En este sentido podemos distinguir tres clases posibles de respuesta filosófica fundamentales ante la mentada crisis de valores del fin de siglo, crisis que por otro lado no es exclusiva de esa época, aunque en ella haya podido darse de un modo más generalizado irrumpiendo en la conciencia colectiva, ya que ha seguido siendo experimentada a lo largo del siglo XX por cada generación y además en todas las épocas la habían vivido los individuos creadores. Distinguiremos, pues, por un lado la respuesta trascendental elaborada por Husserl y prolongada de algún modo por Habermas, por otro lado la respuesta nominalista $o$ analítica de Wittgenstein y en medio la hermenéutica del lenguaje iniciada por Heidegger y uurbanizada" por Gadamer.

Husserl pretende superar la crisis demostrando, frente a positivismo y psicologismo (sea vitalista o historicista), que el lenguaje está bien arraigado en algo sólido, en una significación pre-lingüística o un sentido pre-reflexivo. Este fundamento estaría vinculado a la vivencia, pero no se reduce a mera subjetividad ya que posee un contenido objetivo que puede ser conceptualizado, alcanzando precisamente en la expresión lógico-lingüística, que le concede universalidad, su adecuado acabamiento. Así pues, si bien el lenguaje no puede acoger totalmente la plenitud del sentido pre-reflexivo, sí capta y expresa lo esencial, su contenido objetivo, llevándolo a su cumplimiento. En cualquier caso, en su evolución posterior el propio Husserl, si bien siguió rechazando el psicologismo, fue reconociendo la importancia del "mundo de la vida" como lugar de surgimiento de un sentido irreductible a ninguna otra instancia y como condición de posibilidad de cualquier otra significación.

En el extremo opuesto Wittgenstein insiste, siguiendo a Kraus, en que el lenguaje descriptivo nos permite elaborar un "modelo» o una "imagen» (bildliche Darstellung) que represente de una manera significativa los fenómenos del mundo, pero no nos sirve para decir las cuestiones relativas a la ética, los valores y la significación de la vida, las cuales sólo son susceptibles de una comunicación indirecta o poética ${ }^{2}$. El sentido del mundo no está dado con los hechos, se encuentra fuera del mundo: hechos y valores quedan así radicalmente separados. Con esta

${ }^{2}$ A. JANIK y S. TOULMIN, op. cit., p. 232-241. 
separación Wittgenstein estaría pretendiendo salvaguardar la autonomía de la ética respecto a las intromisiones del discurso racional universalizador: los significados y valores no preexisten con independencia del lenguaje sino que se constituyen en el interior de una práctica, de una "forma de vida», de un «juego» de vida.

\section{La hermenéutica del lenguaje}

Pues bien, entre la vía trascendental de Husserl y el nominalismo wittgensteiniano se va abriendo camino la vía hermenéutica de Heidegger y Gadamer. Partiendo del diagnóstico del último Husserl que atribuye la crisis de las ciencias y de la cultura a su pérdida de contacto con el mundo de la vida, y asumiendo al mismo tiempo el fracaso de la fenomenología, Heidegger critica la onto-teología de la "presencia» que hace del ser el ente supremo. Esta crítica secularizadora de la metafísica acentúa la contingencia del ser insistiendo inicialmente en su conexión con el tiempo y finalmente con el lenguaje, el cual no es entendido como estructura universal y necesaria sino como evento, envío, trasmisión, mensaje. El ser no es, pues, fundamento, causa, sino don, libertad, abismo (Ab-grund) y es por ello que la verdad puede tener historia, múltiples interpretaciones en las que se da, acaece ${ }^{3}$. Gadamer, por su parte, se propone restablecer la comunicación entre la filosofía y la vida, sacando al pensamiento de su reclusión en la conciencia reflexiva intelectualizada y abstracta, formal y académica, para que se abra al presente, a la existencia, al cuerpo, a lo pre-racional. Para ello no vale con recurrir a la razón ilustrada, científico-abstracta, que es incapaz de penetrar en ese territorio. Tampoco se puede renunciar a la razón: hay que transformar o reformar la razón, elaborar un modelo de racionalidad más amplio y más abierto, más "humano". La ciencia va a pasar a un segundo plano. En vez de interpretar desde ella nuestra racionalidad, ahora es la ciencia la que va a ser contemplada como una de las modalidades de la interpretación humana. La neo-hermenéutica se centra así sobre el problema de la interpretación, para volver a elaborar desde ahí toda la reflexión filosófica. Ahora bien, la interpretación ya no es considerada

${ }^{3}$ Cfr. G. VATTIMO, Ética de la interpretación, Paidós, Barcelona, 1991, p. 41 y ss., 81 y ss. En este sentido Heidegger estaría siguiendo y radicalizando a Schleiermacher cuando crítica las reducciones conceptualistas y voluntaristas de la religión y plantea el problema de la interpretación para mostrar que dogmas, preceptos y obligaciones no son el núcleo de la vida religiosa, no tienen sentido en sí mismos sino en tanto que remiten y apuntan a la experiencia interior de lo divino, que consistiría precisamente en el sentimiento de absoluta dependencia respecto al Creador. 
como un "modo de conocer" sino como el «modo de ser» constitutivo del ser humano y va a quedar vinculada a la palabra, al lenguaje en tanto que auténtico medio de su realización efectiva en el interior del diálogo, de la comunicación, de la convivencia.

La hermenéutica del lenguaje de Gadamer constituye, pues, una crítica de la metafísica, bien que asumiendo su pertenencia a esa tradición. Dicha crítica consiste en una especie de "cura de humildad" filosófica que aplaca la hybris del entendimiento metafísico ( $y$, por tanto, de la doctrina teológica cristiana) asumiendo desde dentro sus propios límites, su parcialidad, su relatividad, es decir, su carácter «humano». Hay que entender en este sentido la sustitución del clásico razonamiento abstracto, necesario e incuestionable, por la interpretación, así como el desplazamiento del motivo de la reflexión desde el ser hasta el lenguaje. No hay propiamente renuncia a la razón, sino un descubrimiento de su condicionalidad lingüística: la razón no está más allá del lenguaje sino que, al igual que el propio ser, es lenguaje. "El ser que puede ser comprendido es lenguaje»"

En este sentido el lenguaje no debe ser pensado desde la metáfora del espejo que devuelve, como copiando, la imagen de lo que se le pone enfrente. Pues, según Gadamer, lo esencial de la copia consiste en que «no tiene otra finalidad que parecerse al original, al modelo copiado" ${ }^{5}$, con la consiguiente cancelación de su propio ser para sí en favor de la mera presentación de lo copiado. Frente a la copia, la representación que el lenguaje instaura es concebida por nuestro autor tomando como modelo la relación que vincula a la obra de arte pictórica (cuadro) con la realidad. La obra de arte auténtica tiene, a diferencia de la mera copia, un ser propio en tanto que es la imagen (Bild) en la que la realidad que le sirve de modelo se representa a sí misma, realizándose. Un cuadro no ha de ser examinado atendiendo a lo que el autor tomó como modelo, pues entonces no veríamos lo que en el cuadro se esta representando sino tan sólo una porción de material aún no transformado o transfigurado (así, si pudiéramos poner a la Gioconda "real", en carne y hueso, frente al retrato de Leonardo, seguramente no encontraríamos en ella nada del misterio de su sonrisa que se "transparenta" en el cuadro). Precisamente lo que importa en la obra de arte es «cómo se representa en

\footnotetext{
${ }^{4}$ H.-G. GaDAMER, Verdad y método, Sígueme, Salamanca, 1977, p. 567.

${ }^{5}$ Ibíd. p. 186
} 
ella lo representado, ganando en ella una plena presencia», es decir, aconteciendo así su verdad articulada. La intención está, pues, dirigida hacia la unidad originaria de la representación y lo representado en mutua concreación:

Cada representación viene a ser un proceso óntico que contribuye a constituir el rango óntico de lo representado. La representación supone para ello un incremento de ser?

Esta relación de representación ontolingüistica podría quedar caracterizada mediante el concepto platónico de la emanación en tanto que exceso de lo uno que, como ocurre en el manantial, no disminuye por su excederse en lo múltiple. Ahora bien, para usar dicho concepto en este contexto es preciso evitar cuidadosamente cualquier reducción de la imagen al arquetipo platónico o modelo, pues precisamente la valencia óntica del lenguaje defendida por Gadamer consiste en el hecho de que en él lo dicho está de algún modo presente (re-presentación): «una imagen sigue siendo una manifestación de lo que se representa, aunque ello sólo se manifieste en virtud de la capacidad autónoma de hablar de la imagen" ${ }^{8}$. Según esto el original sólo es originario en tanto que está representado y trasfigurado en el lenguaje (o, paralelamente, en la imagen):

En la imagen lo representado está ahí en un grado más perfecto, de una manera más auténtica, es decir, tal como verdaderamente es".

En este sentido el lenguaje como imagen o "cuadro" de la realidad se diferenciaría, según nuestro autor, del mero signo extrínseco, convencional, sustitu-

${ }^{6}$ Ibíd. p. 207.

${ }^{7}$ Ibíd. p. 189.

${ }^{8}$ Ibíd. p. 200.

9 Ibíd. p. 206. Podríamos decir que la imagen a la que Gadamer se está refiriendo es una imagen simbólica pues, si bien en Verdad y método suele utilizar la palabra símbolo, contraponiéndola a la imagen artística, como equivalente al mero signo extrínseco, convencional, sustitutivo, en una obra de 1977 titulada La actualidad de lo bello (Paidós, Barcelona, 1991) cambia sustancialmente la terminología y recurre a lo simbólico, «tal como lo entendieron Goethe y Schiller» (p. 90) para caracterizar la obra de arte en cuanto que no sólo remite a algo, «sino que en ella está propiamente aquello a lo que se remite» (p. 91) -cfr. al respecto J. GARCia LeAL, Arte y conocimiento, Universidad de Granada, Granada, 1995-. 
tivo, cuya función consiste en apuntar fuera de sí como mera referencia a algo. El signo (una señal de tráfico, por ejemplo) no pretende atraer la atención sobre su propio contenido, no intenta mostrarse a sí mismo sino anunciar o referirse a algo que no está presente (una curva peligrosa oculta tras un cambio de rasante, digamos). Por el contrario, el lenguaje en la concepción gadameriana, no se limita sólo a referir otra cosa: invita a demorarse en él. No está escindido de lo que representa, sino que participa de algún modo en ello, de tal modo que lo representado experimenta en el lenguaje un incremento en su ser. La especulatividad del lenguaje consiste en este su poder de representación, no siendo ni pura referencia ni mera sustitución. El lenguaje natural no debe su significación a una fundación convencional, sino que le viene de su propia naturaleza y contenido: es símbolo en el que se revela lo real vivido.

Más que como un simple medio de comunicación de algo dado y conocido independientemente, el lenguaje comparece ahora como un medium de conocimiento y de descubrimiento en el que tiene lugar, aunque el hablante no se dé cuenta, una primera interpretación sintética o totalizadora del mundo, el cual viene así a quedar articulado, ordenado, estructurado y distinguido como tal mundo. Ya la simple denominación de lo real comporta una conceptuación que libera a lo particular de su aislamiento, mostrándolo en sus relaciones tanto con otros particulares como con el conjunto del ser, el cual se anuncia de algún modo en el lenguaje si bien queda como un trasfondo no dicho explícitamente.

\section{Simbolismo}

La reflexión filosófica se abre, pues, al lenguaje y al descubrir, como apuntó Nietzsche, que tras él se encuentra la imagen (simbólica) o, como dice Gadamer, que el lenguaje, medium de nuestra comprensión, tiene un fundamento metafórico, la neohermenéutica viene a desembocar en la orilla del «mar" del simbolismo. Recordemos a este respecto que Kant, siguiendo una tendencia predominante en la historia de la filosofía, concibió el ámbito del conocimiento, el "país de la verdad», por contraposición al reino de la ilusión, la superstición e ignorancia, sirviéndose para ello de la imagen de una isla «encerrada por la naturaleza misma en límites invariables" y "rodeada de vasto y tempestuoso mar». El filósofo desconfia de cualquier intento de adentrarse en ese océano y advierte que "bancos de nieblas y hielos que pronto se derretirán fingen nuevas tierras que incesantemente engañan con vanas esperanzas al marino ansioso de descubri- 
mientos, encadenándolo a locas empresas que aventuras que nunca puede abandonar ni llevar a buen término» ${ }^{10}$.

Así, frente al cerrojazo de la filosofía que clásicamente se constituye a sí misma mediante la exclusión del simbolismo (así como la Iglesia se estableció por la negación de las herejías gnósticas y la ciencia moderna poniendo entre paréntesis el sentimiento y la imaginación), la hermenéutica descubre finalmente su fundamento simbólico, iniciando, aunque de un modo muy prudente y limitado, la exploración de ese "mar desconocido" (al menos para la filosofía clásica, pues desde siempre ha sido surcado por poetas, místicos, soñadores, visionarios, locos, aventureros...). En este sentido se puede entender la afirmación de Gadamer de que "es una tarea propiamente filosófica - al menos para la tradición europea de la filosofía que vive mirando de reojo a la ciencia - hacer justicia a la dimensión de lo mítico [...] La tendencia objetivadora de la conciencia (y no sólo de la moderna ciencia) debe ser compensada con la experiencia mítica" ". En cualquier caso, para la hermenéutica del lenguaje el simbolismo representa de un modo u otro su límite, pues, como heredera del intelectualismo de la filosofía clásica, concibe el lenguaje como medium de la conciencia reflexiva, la cual patina sobre la superficie del símbolo, no puede interpretarlo salvo de una manera reductiva que anula su carácter simbólico, su diferencia y trascendencia respecto a la conciencia. Si se aborda desde la mera conciencia el símbolo no es propiamente interpretable.

Fue Nietzsche quien siguiendo la línea del primer romanticismo constató el alcance filosófico del simbolismo. En su polémica con el platonismo en defensa de la primacía del arte sobre el conocimiento Nietzsche descubre que detrás del concepto que emplea la ciencia en su organización de la experiencia se encuen-

10 I. KaNT, Crítica de la Razón pura, vol. II, Losada, Buenos Aires, 1980, p. 9 (cfr. al respecto M. Le Doeuf, Limaginaire philosophique, Payot, París, 1980, p. 17 y ss.). En la actualidad el físico J.-M. Lévy-Leblond dice que para poder concebir clásicamente el saber como una isla o continente hay que imaginar sus costas como curvas fractales. Se trataría de costas formadas por peninsulas separadas por golfos. Las penínsulas a su vez, estarian horadadas por bahías que separan largos cabos, cuyas costas se recortan formando ensenadas, que a su vez nos remiten a calas... "En otras palabras, la longitud de esta costa aumenta sin cesar cuando crece la precisión con que se define. En realidad, la longitud exacta del límite entre tierra y mar es infinita" -cfr. M. CAZENAVE (dir.), Diccionario de La ignorancia. Seix Barral, Barcelona, 2000, p. 21.

"H.-G. Gadamer, Mito y razón. Paidós, Barcelona, 1997, p. 64. 
tra la imagen y el esquema que el instinto artístico o mitopoético del lenguaje ha impuesto al caos originario confiriéndole un sentido humano. Para Nietzsche la interpretación precede al concepto como órgano de configuración de valores que posibiliten y promuevan la circulación de la vida. La ilusión y la ficción, la metáfora y la mentira no se contraponen al conocimiento, sino que lo fundan. Además Nietzsche aplica el concepto de interpretación a la propia actividad filosófica, concibiéndola, según reza uno de los subtítulos proyectados para la Voluntad de poder, como «ensayo de una nueva interpretación de todo acontecer» $^{12}$.

En el campo de la psicología ha sido C. G. Jung quien, desmarcándose de Freud, ha descubierto el carácter no meramente sintomático sino propiamente expresivo del símbolo. Así, mientras que el concepto o el signo convencional es un instrumento de comunicación elaborado conscientemente y conscientemente comprobado y controlado que tiene un carácter referencial, el símbolo sería más bien una expresión espontánea de la personalidad entera, es decir, que en él se expresa tanto la personalidad consciente como la inconsciente, tanto «las funciones espirituales más altamente desarrolladas» como «los movimientos más bajos y primitivos" ${ }^{13}$, por lo que siempre contiene algo desconocido, inatrapable, misterioso, innombrable. «Ningún símbolo es simple. Simples no son más que el signo y la alegoría. Pues el símbolo oculta siempre una realidad compleja, tan fuera de toda expresión verbal que no es posible

12 Cfr. J. Conill, El poder de la mentira, Tecnos, Madrid, 1997, p. 95 y ss., donde plantea la cuestión de la interpretación remitiendo a J. Figl, Interpretation als philosophisches Prinzips, Gruyter, Berlín, 1982. En el mismo sentido cfr. G. VATTIMO, Introducción a Nietzsche, Península, Barcelona, 1987. Para una revisión en positivo y en negativo de Nietzsche desde la hermenéutica simbólica cfr. A. ORTIZ-OsÉs, La nueva filosofia hermenéutica, Anthropos, Barcelona, 1986, y Así no bablo Zaratustra, Anthropos, Barcelona, 1989. Para situar la ontología trágica de Nietzsche en conexión con el pensamiento simbólico, cfr. P. LANCEROS, La herida trágica. El pensamiento simbolico tras Hölderlin, Nietzsche, Goya y Rilke, Anthropos, Barcelona, 1997.

${ }^{13}$ C. G. JUNG, Tipos psicologicos, Edhasa, Barcelona, 1994, p. 559. Jung diferencia la fantasía pasiva, que sería la mera irrupción de contenidos inconscientes, de la fantasía activa que es desencadenada por una actitud expectante, «intuitiva». "La fantasía pasiva necesita siempre de una crítica consciente, si no se quiere que haga valer unilateralmente el punto de vista del opuesto inconsciente. En cambio, la fantasía activa, producto por un lado, de una actitud consciente no contraria a lo inconsciente y, por otro, de procesos inconscientes que no tienen un comportamiento opuesto a la consciencia, sino un comportamiento meramente compensador, no necesita de esa crítica, sino sólo de comprensión" (ibíd., p. 511). 
expresarla en el acto" ${ }^{14}$. La reflexión consciente no agota, pues, la riqueza del símbolo, que engloba también lo inconsciente, no puede traer al lenguaje, poner en palabras, el sentido que impregna y anima al símbolo en cuanto tal, es decir, al símbolo vivo. Si un símbolo se puede verter totalmente en palabras es porque ya no es un símbolo: o bien ha dado ya todo lo que llevaba dentro, muriendo de «muerte natural» o bien el ímpetu del pensamiento que pretendía penetrarlo con la lógica lo ha "matado", reduciéndolo. La conciencia ha de respetar el misterio del símbolo, ha de aceptar, en todo caso, que no puede agotarlo, que no puede comprenderlo totalmente, adoptando una actitud simbólica ${ }^{15}$. Manteniendo ese respeto es posible ampliar la psicología aplicándola a esas esferas que el lenguaje religioso se esfuerza por expresar y a las que la ciencia no ha tenido acceso:

Lo único que hacemos es desplazar un poco más atrás los símbolos y sacar a la luz del día un fragmento de su reino, pero sin incurrir en el error de creer que con ello hemos creado algo más que meramente un símbolo nuevo del mismo enigma que ha sido enigma para todos los tiempos anteriores a los nuestros. También nuestra ciencia es un lenguaje figurado, pero en el aspecto práctico se adapta mejor que la vieja hipótesis mitológica, la cual se expresaba en nociones concretas, en vez de hacerlo como nosotros en conceptos $^{16}$.

Desde el ámbito de la filosofía ha sido Cassirer quien ha descubierto y recuperado el valor epistemológico y formal del simbolismo partiendo de un neokantismo ampliado y enriquecido que, bajo la influencia de A. Warburg y su grupo, revaloriza la tercera Crítica kantiana estableciendo un esquema plural en el que comparecen como irreductibles entre sí las modalidades fundamentales del simbolismo cultural de acuerdo con las cuales tiene lugar la configuración del mundo humano: la forma mítica (religión y arte), la forma lógica (matemáticas y ciencias naturales) y la forma lingüística (lenguaje natural, filosofía y ciencias de la cultura) que, teniendo el mismo origen que la primera, apunta hacia la segunda, mediando así entre ellas ${ }^{17}$.

14 R. Hostie, Del mito a la religión en la psicologia de C. G. Jung, Amorrortu, Buenos Aires, 1977 , p. 53.

${ }^{15}$ Cfr. C. G. Jung, op. cit., p. 557 así como 544.

16 Ibíd. p. 301.

17 Cfr. E. Cassirer, Antropología filasófica, Fondo de Cultura Económica, México, 1977. 


\section{Hermenéutica simbólica}

Pues bien, entre hermenéutica y simbolismo se plantea de entrada una oposición similar a la que existe entre la consciencia y lo inconsciente, una oposición que no es, empero, absoluta sino que puede ser mediada. Tal es la tesis desatrollada por A. Ortiz-Osés a lo largo de su compleja obra en la que va realizando una implicación de la hermenéutica con el simbolismo, los cuales quedan reunidos sin confundirse en una nueva hermenéutica simbólica. En tanto que hermenéutica la filosofía de Ortiz-Osés se centra en el lenguaje como objeto y sujeto de interpretación, pero en tanto que simbólica no lo considera con un interés meramente epistemológico sino propiamente antropológico: lenguaje dice diálogo ético-reflexivo (espiritual) y consenso racional, pero desde una apalabramiento anímico-existencial y un consentimiento interpersonal ${ }^{18}$. El lenguaje queda así comprendido como relato de una determinada relación vivida, de una determinada experiencia antropológica: se trata de los lenguajes culturales en tanto que ámbitos de manifestación (Heidegger) en los que se configura simbólicamente el sentido humano dando lugar a las diversas cosmovisiones, axiologías y mito-logías que el autor agrupa en torno a tres tipos fundamentales: el matriarcal-naturalismo, el patriarcal-racionalismo (reactivo frente al anterior) y el fratriarcal-personalismo, como proyecto inagotable de implicación de ambos.

Ortiz-Osés elabora una interpretación simbólica de la metafísica clásica, presidida por el concepto de ser, que atiende al hecho de que su lenguaje se estructura mediante una serie de oposiciones (como las de devenir y ser, cuerpo y espíritu, materia y forma, potencia y acto, lo mudable y lo permanente, lo sensible y lo inteligible, lo contingente y lo necesario, dóxa y epistéme, etc.) en las que el segundo término obtiene una valoración positiva mientras que el primero queda cargado de connotaciones negativas. Esta oposición que el lenguaje de la filosofía plantea en un ámbito conceptual remite, según Ortiz-Osés, a otra oposición más básica o infraestructural en el nivel antropológico o psico-social: la existencia de dos lenguajes culturales, dos cosmovisiones religiosas, dos mitologías o formas de vida que coexisten jerarquizadas en el interior de la cultura griega. Tendríamos por un lado la tradición cultural autóctona (tal como emerge en la Creta minoica) con su mitología de signo matriarcal-telúrico, heredera (al igual

18 Cfr. A. ORTIZ-OSÉs, Comunicación y experiencia interhumana, Desclée de Brouwer, Bilbao, 1977, p. 87. 
que la vasca, interpretada por primera vez por nuestro autor) de la cultura neolítica de la Gran Diosa, que encuentra su expresión simbólica en el semi-subterráneo Laberinto; por otro lado comparece la tradición de los diversas poblaciones indoeuropeas que se fueron asentando en las orillas del mediterráneo con su mitología patriarcal-celeste presidida por Dyaus-Zeus (y ejemplificada en el elevado y simétrico Partenón) que se habría impuesto sobre la anterior, manteniéndola oprimida y reprimida ${ }^{19}$. Según esto, el concepto de ser (y, con él, el lenguaje conceptual de la filosofía clásica) se levantaría, aunque de un modo velado, sobre un simbolismo (el mito patriarcal-heroico) al que concede reconocimiento y expresión lingüística, mientras que silencia la otra simbología matriarcal. Dicho concepto no sería entonces propiamente un símbolo, sino más bien un síntoma del predominio unilateral de lo patriarcal sobre lo matriarcal, y estaría por ello reclamando una reinterpretación (fratriarcal) compensadora.

La re-interpretación simbólica de la tradición metafísica (y paralelamente también de la tradición filosófico-teológica cristiana) realizada por Ortiz-Osés comporta pues una trasgresión de la axiología patriarcal y su imperativo de verdad, sumergiéndose cuasi-regresivamente en las aguas preconceptuales de las que surge la consciencia, para desde ellas proceder a una reversión o trasvaloración de los valores guiada por la pretensión de sentido (la interpretación como retroprogresión). La metafísica se reconvierte así en hermenéutica simbólica de la(s) cultura(s), en inter-cultura o búsqueda intercultural de un consentimiento con el/lo otro como necesario complemento de nuestra unilateralidad (individual y colectiva). La filosofía se proyecta así como un amistamiento o amigamiento de los contrarios realizado mediante la interpretación (consciente) de los productos culturales (textos: érgon) como interpretaciones (simbólicas), como resultado de un proceso (energeia) en el que la realidad inmediatamente vivida, lo sentido en la oscuridad de la inconsciencia sale a la luz de la conciencia, aparece, se expresa, manifiesta o revela, trasponiéndose en imagen ${ }^{20}$. Lo real, que estaba encerrado en sí, se raja, se abre, se desdobla y redobla generando símbolos, "máscaras" (Campbell), imágenes, palabras, conceptos, ideas e ideales en los que se hace pre-

19 Esta interpretación es un desarrollo de la tesis formulada por Bachofen sobre el derecho materno latente tras las formas clásicas del derecho griego y por Nietzsche al descubrir el impulso dionisíaco presente en la tragedia y paulatinamente reprimido por el «espíritu socrático".

${ }^{20}$ La palabra interpretación tiene, pues, un significado doble: por un lado dice explicación y por otro implicación (cfr. A. ORTIZ-OSÉs, Cuestiones fronterizas, Anthropos, Barcelona, 1999). 
sente (representándose al tiempo que se institucionaliza), con lo que se establece la diferencia entre lo sagrado y lo profano, lo interior y lo exterior, el mensaje y el medio, el sentido y el texto, abriéndose una tensión (insuperable) entre esos dos polos opuestos, una "herida" que está a la base de todo desarrollo o despliegue cultural (es decir, humano). Pues bien, la tarea de la hermenéutica simbólica cultivada por Ortiz-Osés consiste precisamente en el intento inacabado e inacabable de suturar (simbólicamente) esa herida (real). Pues la cultura, remedio simbólicamente proyectado por nuestra naturaleza desgarrada, a medida que se consolida se va literalizando, va perdiendo la memoria de su carácter culturalsimbólico, y se naturaliza, formaliza y burocratiza, esclerotizándose, perdiendo el alma, hasta el punto de que el remedio puede resultar peor que la enfermedad (como vio Nietzsche). Mantener vivo ese recuerdo devolviendo el alma a nuestro mundo desencantado y a nuestras relaciones funcionalizadas: tal es la propuesta cultural de la hermenéutica simbólica iniciada por Ortiz-Osés y en la que desde distintas perspectivas trabajamos también un pequeño grupo de profesores formado filosóficamente en su entorno deustense e integrado por P. Lanceros, que se ocupa de las relaciones político-literarias de la hermenéutica, J. Beriain, que trabaja el campo de lo socio-político en colaboración con C. Sánchez Capdequí, J. Balza, centrado en la lectura de la filología vasca desde la filosofía y la simbología, M. Egiraun, que cultiva una hermenéutica situacionista, así como el que esto escribe, que se dedica más bien a los aspectos filosóficos y psico-antropológicos de la hermenéutica ${ }^{21}$.

En este sentido cabe apuntar, como ha hecho el propio Ortiz-Osés, que a la base del giro lingüístico de la hermenéutica se encuentra un giro antropológico, el mismo giro antropológico que marca en Sócrates el inicio de la filosofía. La filosofía de Sócrates puede ser concebida, según afirma P. Hadot, como explicación-exposición dialógica de la opción de vida implicada en el «conócete a ti

21 P. LANCEROS, La modernidad cansada, Ediciones Libertarias, Madrid, 1994; Avatares del hombre. El pensamiento de Michel Foucault, Universidad Deusto, Bilbao, 1996; La herida trágica, Anthropos, Barcelona, 1997; J. BERIAIN, Representaciones colectivas y proyecto de modernidad, Anthropos, Barcelona, 1990; La integración en las sociedades modernas, Anthropos, Barcelona, 1996; La identidad colectiva: vascos y navarros, Haránburu Editor, San Sebastián, 1998; C. SÁNCHEZ CAPDEQUI, Imaginación y sociedad, Tecnos, Madrid, 1999; J. BALZA, Hermenéutica y lenguaje. Exploración de las categorias del euskera, Tesis Doctoral, Universidad Deusto, 1997; L. GARAGALZA, La interpretación de los simbolos. Hermenéutica y lenguaje en la filosofia actual, Anthropos, Barcelona, 1990. 
mismo» ${ }^{22}$. Esa opción de vida, que no proviene de la reflexión filosófica sino que la funda, exige "un cambio total de vida, una conversión de todo el ser, un cierto deseo de ser y de vivir de cierto modo" ${ }^{23}$. Sócrates abandona, como los sofistas, las reflexiones físicas y cosmológicas, pero a diferencia de estos, que se vuelcan en la actividad pública, va a centrarse en la observación y el "cultivo" de la psique, sede de la dimensión ética individual, y en la revisión continua de los pensamientos y comportamientos propios en el contexto de un diálogo también inacabable. En este sentido la filosofía consiste inicialmente en un ejercicio practico-teórico para "volverse mejores y más mesurados»: aprender filosofía era "asimilar un modo de vida y practicarlo" ${ }^{24}$. El posterior divorcio entre el modo de vida y el discurso filosófico se debe, según este autor, al auge del cristianismo eclesiástico o escolástico, en el interior del cual la filosofía va quedando reducida durante la Edad Media a mero "material conceptual utilizable en las controversias teológicas" ${ }^{25}$.

En el ámbito del cristianismo originario o nazareno podemos reconocer un giro antropológico similar contenido en la doctrina o, mejor, misterio de la "Encarnación del Verbo», que afirma que la Sabiduría eterna ha penetrado dentro del mundo, de la historia, tornándose ser humano, humanizándose ${ }^{26}$. Esta nueva dignidad del ser humano va a encontrar su expresión en la noción de "persona" acuñada inicialmente dentro de la reflexión teológica sobre la Trinidad en un intento de salvar la diferencia entre el Padre, el Hijo y el Espíritu sin caer en el triteísmo ${ }^{27}$. Frente al sustancialismo (estático) la noción de persona que va a ser-

22 Cfr. A. OrTIZ-Oses, La razón afectiva, San Esteban, Salamanca, 2000.

${ }^{23}$ P. HADOT, ¿Qué es la filosofia antigua?, Fondo de Cultura Económica, México, 1998, p. 13.

24 Ibíd. p. 170.

25 Ibid. p. 275.

${ }^{26}$ Como apunta Juan Damasceno, una consecuencia de la Encarnación es que se anula la prohibición veterotestamentaria de representar en imágenes lo divino (cfr. M. ElIADE, Historia de las creencias y de las ideas religiosas, vol. III, Ed. Cristiandad, Madrid, 1978, p. 73). En este sentido, el primer icono sería la imagen que quedó marcada en el velo con el que Verónica enjuagó el rostro de Jesús (cfr. G. Durand, LImaginaire, Hatier, París, 1994, p. 11).

${ }^{27}$ Cfr. A. MORENO, El aro y la trama, C.I.P., Caracas, 1994, p. 497 y ss. R. Panikkar recoge la versión más dinámica de este misterio en la siguiente fórmula: "Todo cuando el Padre (Absoluto) es lo transmite (kénosis) al Hijo. Todo cuanto el Hijo recibe lo entrega a su vez al Padre. Esta donación (al Padre, en última instancia) es el Espíritu" (R. PANIKKER, La Trinidad, Siruela, Madrid, 1998 , p. 69). En el interior de la cultura griega cabe señalar una superación homóloga del sustancialismo en el neoplatonismo de Plotino con la tesis de que el Uno está por encima del ente (y su 
vir para caracterizar al ser humano acentúa la importancia y aun primariedad de la relación (dinámica) tanto externa (inter-humana o comunitaria) como interna (intimidad: Agustín). La persona entendida por Juan Damasceno como «lo que se expresa a sí mismo» va a ser definida por Agustín como "relación» y transferida al ser humano, a cada ser humano, que se convierte así, por ser-en-relación-a-Dios, en fin en sí mismo, adquiriendo un valor incondicional al que queda subordinado el ámbito de las cosas, el "mundo" y sentando las bases de una igualdad universal $^{28}$.

Estas dos tradiciones «antropológicas» (la socrática y la nazarena) siguen vías más o menos independientes, pero vienen a confluir a través de Petrarca, Eckhart, Nicolás de Cusa, etc., en el sincretismo «humanista» del Renacimiento que hace radicar la dignidad del hombre en ser "grapa" del mundo: en virtud de su creatividad, que deriva de haber sido creada a imagen y semejanza de Dios, el alma humana enlaza lo inferior con lo superior, el cuerpo con el espíritu, la sensibilidad con el entendimiento, la tierra con el cielo. En este sentido habría que hablar, como ha hecho J. Hillman, de un humanismo más centrado en el alma que en el propio hombre, es decir, de un humanismo "anti-humanista" por cuanto que "almista" o "animista", ya que el alma no se identifica con lo estrictamente humano del sujeto consciente, sino que consiste precisamente en la relación con lo no propiamente humano, con lo trashumano o traspersonal (sea natural, demónico o divino $)^{29}$. En tanto que dotado de alma el ser humano concreto, cada ser

contrapartida: lo uno es un no-ente). Con ello, apunta Aubenque, «Plotino no pretende poner en cuestión la coherencia de la ontologia clásica: pero esta ontología se halla en Plotino relativizada, situada en un lugar segundo, que es el que le corresponde a la segunda hipóstasis” - P. AUBENQUE, "Plotino o la superación de la ontología clásica griega", Los cuadernos de la Gaya Ciencia, vol. II (1975), p. 10-.

${ }_{28}$ Cfr. L. Dumont, Ensayos sobre el individualismo, Alianza, Madrid, p. 42. A. Moreno considera, empero, que Agustín supera conceptualmente el sustancialismo-individualismo, pero lo hace desde categorías de la filosofía griega, es decir, pensando desde el individuo, sin establecer otra episteme. «Ś́lo en nuestros tiempos el concepto de persona adquiere rasgos verdaderamente novedosos. El concepto clásico más avanzado de la persona como expresión (de sí), manifestación, evoluciona al de apertura total, comunicación, tras-cendencia... el centro del hombre no está en el hombre sino fuera de él, en el otro. Esto es, el hombre es un descentrado, un fuera-de-sín (op. cit., p. 500). Habría pues que pensar desde la relación, no desde el individuo, y afirmar que "la persona es intrínsecamente relación. La relación es su existencia concreta, su ser-existente" (ibíd. p. 502).

${ }^{29}$ Cfr. J. Hillman, Re-imaginar la psicologia, Siruela, Madrid, 1999, p. 382 y ss., donde, recordando que la palabra humanismo empezó a utilizarse en el siglo XIX, denuncia la "falacia huma- 
humano, es un «microcosmos» en el que concurren todas las líneas del macrocosmos cobrando una significación humana, una expresión simbólica: como escribió Nicolás de Cusa a Giuliano, «todas las cosas se giulanizan en tì " ${ }^{30}$. En el individuo que atiende a su alma y recorre su senda los opuestos se van reuniendo y armonizando: es un centro en el que se equilibran los extremos (extremos que coinciden en su origen: origen que de acuerdo con la definición de Cusa sería la circunferencia cuyo centro está en todas partes y su circunferencia en ninguna). En este sentido, Pico della Mirandola afirma que «entre Dios y el hombre hay esta diferencia: que Dios contiene todas las cosas en sí mismo porque es su origen, mientras que el hombre contiene todas las cosas porque es su centron ${ }^{31}$. Pero ahora, frente al propio Pico y al humanismo ascensional o centralizador (liberal-abstracto), que corre el riesgo de recaer en el esquema de la metafísica tradicional - bien que desplazando el fundamento desde el Ser hasta el hombre (y su yo-consciencia) - ese centro ha de ser concebido no como un centro absoluto sino como un "centro descentrado" en y por un lenguaje-símbolo que en la interpretación lo abre (descensionalmente: catafóricamente) a lo otro de sí (inconsciente) desfundamentándolo (anarcohumanismo que no responde a la determinación racional del ente sino a lo que en la convivencia anímica emerge como con-sentido). Podríamos hablar pues, como ha hecho A. Ortiz-Osés, de un «humanismo hermenéuticon en el que lo específicamente humano es la interpretación simbólica que descentra al sujeto-intérprete en virtud de lo consentido con el/lo otro: «El hombre trata de remediar simbólicamente la propia escisión produci-

nística" que consistiría en confundir la psique con lo humano y con el sujeto consciente. Cfr. también C. G. JUNG, Tipos psicológicos, p. 298: «El alma no pierde nunca su posición intermedia. Por ello ha de ser invocada como una función situada entre el sujeto consciente y las profundidades de lo inconsciente, inaccesibles al sujeton. Una reciente investigación filológica que compara la lengua ibera con el euskera, el etrusco y el minoico apunta que la palabra "ánima" proviene del trasfondo cretense de la cultura europea. Dicha palabra estaría presente en las inscripciones funerarias del llamado "disco de Festos" que sería precisamente una de las primeras composiciones sobre el "viaje del alma» al más allá subterráneo (cfr. A. ARNÁIZ y J. ALONSO GARCIA, Minoicos, cretenses y vascos, un estudio lingüistico, Estudios Complutenses, Madrid, 1999, p. 187 y ss. Dicho "viaje" tiene lugar a través de la simbólica "puerta” («ate» en euskera) donde reside la Señora de la vida y de la muerte Atana, Atena o Dikatina -en euskera ate-an = en la puerta, ibero atin, etrusco atanolatin- (p. 80, 46; cfr. también A. ARNÁIZ y J. AlonsO, El origen de los vascos, Estudios Complutenses, Madrid, 1998, p. 102).

${ }^{30}$ Citado por T. Moore, El cuidado del alma, Urano, Barcelona, 1998, p. 335.

31 P. WIND, Los misterios paganos, Barral, Barcelona, 1972, p. 101. Wind concluye a este respecto que "el equilibrio no es más que un eco de la trascendencia". 
da por su misma aparición a través de un lenguaje suturador. El lenguaje hermenéutico constituye ese espacio abierto (celeste) del tiempo humano-terrestre del sentido, el cual es más que lo mentado: lo consentido" ${ }^{32}$. El consentimiento transgrede, pues, lo meramente mentado, el significado instituido, y se inmerge en "lo que no tiene nombre» y al asumirlo le confiere significación humana, sentido consentido. Estaríamos así dentro de lo que E. Grassi ha llamado el «humanismo no platonizante»: «Esta tradición "humanística" no parte del problema del conocimiento racional del ente. El Humanismo hace del problema de la palabra su punto de arranque, considerando que es en su ámbito donde se experimenta la interpelación existencial del ser ${ }^{33}$.

La hermenéutica simbólica proyectada por Ortiz-Osés se apoya precisamente en ese punto de concurrencia pagano-cristiano que posibilita una visión transversal de nuestra realidad. Pues, lo queramos o no, somos herederos de un patrimonio cultural: ni logramos liberarnos totalmente de sus defectos, ni podemos renunciar a sus beneficios. Asumir críticamente la propia herencia reinterpre-

${ }^{32}$ Cfr. A. OrTIZ-OSÉS, «Nueva presentación», en A. Ortiz-Osés y P. Lanceros (eds.), Diccionario interdisciplinar de Hermenéutica, Universidad de Deusto, Bilbao, 2001.

33 E. GRASSI, La filosofla del humanismo, Anthropos, Barcelona, 1993, p. 177. Según apunta E. Grassi, dicho "humanismo" se da en Italia desde la segunda mitad del siglo XIV hasta el último tercio del XV, viéndose interrumpido por el giro platónico propiciado por Ficino, y es prolongado posteriormente por autores como Nizolio o Vives y Gracián (con su teoría del ingenio) desembocando en la obra de Vico (cfr. E. Grassi, Vico y el humanismo, Anthropos, Barcelona, 1999, p. 93). Frente a la interpretación más habitual a partir de Burckhardt, Jaeger, Garin, etc. (seguida también por Heidegger), que ve la esencia del humanismo en el redescubrimiento del hombre y de sus valores inmanentes, E. Grassi sostiene que no se centra propiamente en el hombre sino que lo central es «la cuestión del contexto originario, del horizonte o 'apertura' en que aparecen el hombre y su mundo" (p. 98). Frente a la tradición metafísica, para la que el lenguaje «sólo desempeńa la función de expresar la determinación racional de los entes» (p. 202), la tradición humanista sitúa la fuente del mundo humano en la fantasía (p. 118), viendo en el lenguaje metafórico el ámbito en el que "lo ente queda claro, se abre en su significado para el hombre»: "mediante el lenguaje metafórico lo ente se revela entrando en la apertura del mundo humano" (p. 149). Mientras que el pensamiento occidental, desde Platón a Hegel, concede la primacía a la lógica y al lenguaje racional, incapaz de alcanzar las pasiones, la tradición humanista reconoce el alcance filosófico de la retórica: "No es la antropología o la filosofía platónica lo que caracteriza la problemática fundamental y específicamente nueva del Humanismo, sino la cuestión de la respuesta existencial a la interpelación del ser, por obra de la cual adquiere el ente su diverso significado en consonancia con la respectiva situación concreta. Este problema será dilucidado en y a través de la palabra, y no por medio de la definición racional del ente" (E. Grassi, La filosofía del humanismo, Anthropos, Barcelona, 1993, p. 180). 
tándola proyectivamente es la alternativa realista, evitando tanto la repetición dogmática y mecánica como las actitudes meramente iconoclastas. Y asumir la herencia greco-cristiana desde ese punto de concurrencia permite conjurar un peligro real como es su marcada propensión al dualismo: su tendencia a dividir todo en dos partes estableciendo una frontera que las separa nítidamente. Lo peor, de todas formas, no radica en la propia tendencia, que quizá sea una tendencia universal y necesaria del pensamiento humano, sino en el hecho de creerse que la realidad es así efectivamente: que "hay» una frontera real que como un abismo separa absolutamente a buenos y malos, espíritu y cuerpo, cultura y naturaleza, amor y odio, mito y razón, oscuridad y luz, lo sagrado y lo profano, etc. Con ello la distinción se instituye como perenne, se consagra la incomunicación como sinónimo de virtud. Los "habitantes" de la frontera quedan, así, suprimidos. Pues bien, la hermenéutica simbólica de Ortiz-Osés se empeña en mantener vivo el recuerdo de que cada frontera que se absolutiza está ocultando algo valioso y necesario en la contextura de lo real: de ahí su carácter relacional y su intento de implicar los contrarios. Situarse ahí no significa detenerse en el límite, sino transitarlo. Este tránsito se realiza a través del hilo conductor del simbolismo, ya que la razón simbólica no es una razón pura o purista sino impura y relacional. El alma sería, concretamente, el ámbito de una tal razón, últimamente caracterizada como "razón patética» o "afectiva", y tendría un alcance metafísico pues, como realiza la animación del ser, constituye simbólicamente el corazón de lo real ${ }^{34}$.

${ }^{34}$ Cfr. A. ORTIZ-OsÉs, La razón afectiva, op. cit. 